\title{
Building Performance Evaluation for Adaptive Reuse: A Multi-Criteria Approach
}

\author{
Buket Giresun Erdoğan*, Çiğdem Polatoğlu \\ Department of Architecture, Faculty of Architecture, Y1ldız Technical University, Istanbul, 34349, Turkey
}

Received February 10, 2021; Revised June 15, 2021; Accepted October 15, 2021

\section{Cite This Paper in the following Citation Styles}

(a): [1] Buket Giresun Erdoğan, Çiğdem Polatoğlu, "Building Performance Evaluation for Adaptive Reuse: A Multi-Criteria Approach," Civil Engineering and Architecture, Vol. 9, No. 7, pp. 2427 - 2440, 2021. DOI: 10.13189/cea.2021.090728.

(b): Buket Giresun Erdoğan, Çiğdem Polatoğlu (2021). Building Performance Evaluation for Adaptive Reuse: A Multi-Criteria Approach. Civil Engineering and Architecture, 9(7), 2427 - 2440. DOI: 10.13189/cea.2021.090728.

Copyright $@ 2021$ by authors, all rights reserved. Authors agree that this article remains permanently open access under the terms of the Creative Commons Attribution License 4.0 International License

\begin{abstract}
Adaptive reuse is a common approach for buildings that no longer serve their original function despite their good physical conditions. Such applications require the examination of the building regarding its qualities and capabilities. The focus of this study is the capability of the buildings to correspond to the user's requirements following adaptive reuse processes, and the effects of new functions on the building performance optimization. Achieving reliable data in building performance evaluation will be possible only through the correct definition and association of the criteria. This study examines the adaptive reuse of Mugla Museum, a former prison building, through archive research, plan analysis, observations, and interviews. The result of the study has shown that the functional and perceptive performance of Mugla Museum is neutral, while the technical performance of the building has been found to be good. The building corresponds to its function with average performance, and the level of performance has the potential to be increased through adjustments in the building program or capacity increase. The study has shown that performance evaluation is necessary for determining the strengths and weaknesses of buildings. Within this context, developments in assessment methods would contribute to the betterment of adaptive reuse processes.
\end{abstract}

Keywords Adaptive Reuse, Building Performance Evaluation, Reuse, Post-Occupancy Evaluation

\section{Introduction}

Instead of the destruction of buildings that no longer correspond to their original functions due to aging or any reason, it is a quite common approach to transform, and reuse such structures since the socio-cultural, economic, and environmental [1], [2] factors. Today, adapting existing buildings for the sake of their sustainable use has become a creative and efficient process [3]. Moreover, adaptive reuse also plays an important role in the manners of inspiration for future sustainable tourism and building practices [4] in both local and global contexts. Generally, adaptive reuse is based on the implementation of innovative technological solutions which allow historical structures to be adapted to the modern requirements in terms of performance and aesthetics [5] However, examinations regarding the quality and spatial sufficiency are required for the adaptive reuse process of such structures. Evaluating the performance of adapted buildings would offer prospective insight to the coming transformation design studies and betterment of existing buildings. Therefore, building performance evaluation for adaptive reuse should focus on determining whether the re-experienced spaces correspond to the occupant requirements and the possible effects of the new function on the building performance, as well as ensuring sustainable use of the building.

To extend the efficient life of the building, it is important to construct a knowledge of performance and to make sure the administrators and occupants of the building act according to such knowledge. The key 
criteria determined towards extending the effective life of a building can trigger decisions regarding attributing more or different purposes of use to the building.

In the last 20 years, there has been a focus on early-stage design and many conceptual innovations have been developed regarding building performance optimization [6] The usage of the concept "building performance" in the field of architecture dates back to the 1970s [7] However, performance evaluation of the adapted buildings has been brought to the architectural agenda recently. Therefore, the number of studies is less in this field, compared to the studies focusing on the performance evaluation of new buildings or performance-based building design.

According to this study, the adaptive reuse process can be evaluated through the existing building, the new function, and the occupants of such buildings. The feasibility of the adapted building and the user's perception of the adaptation can be deduced through performance evaluations of the buildings. This study aims to measure the effect of the adaptive reuse process on the performance of the building, to examine whether the case study corresponds to its new function and how the user perceives the building performance. With this study, a conceptual framework for determining the strengths and weaknesses of an adapted building is provided in the literature. This will also benefit improvement for current or future adaptive reuse implementations in the context of performance.

\section{Background}

Apart from introducing how a structure should be built, the approach of performance presents result-oriented thinking and working practice [8] demonstrating the elements a building should include. As stated by Preiser [7] the concept of performance in buildings has been developed by Eberhard in the 1960s and has been used in the field of architecture starting from the late 1970s.

Gibson [8] divides the performance approach into pieces as "the system" and "space". It has been stated that the performance approach can be applied to each of these parts. However, the performance approach can be applied not only to parts but also to a system as a whole, even at an urban scale [9]. "At this point, performance-based design and building of built environments to evaluate alternatives in a comparative way seems to have increased attractiveness for individuals/companies/institutions/local authorities of policymakers [9]."

Preiser and Vischer [10] and Szigeti and Davis [11] relate the performance approach with the lifecycle of the building, declaring that the approach can be applied to any step in the process.

The approach of the performance-based building focuses on the aimed performance required by the building process and user requirements [11]. It identifies the requirements and practicalities of the buildings, places, or the function, starting from the beginning of the process.

As the literature demonstrates, performance-based building approach takes part throughout the building production process, from the preparation of the building program to design and implementation processes [8], [11], development and marketing of the building [8], structuring design guidelines [8], auditing, approval or certification and quality assurance processes [8], [12], as well as developing international standards and agreements [13] regarding building production. The advantages of performance evaluation can be summarised as precise measurement and increased objectivity in building assessment [14], recognition of innovations, and encouraging the use of new technologies [12]-[14], decreased building costs [13], contributing in the decision processes [12], [14] and determining whether expected results in building usage are fulfilled or not.

Although different perspectives regarding building performance approaches have been embraced by different researchers, the common ground is that this approach presents an important step towards the confirmation of existing performance standards or standards that need to be developed for a certain type of building.

\subsection{Building Performance Evaluation (BPE)}

Building performance evaluation requires clear expressions, performance measurements, and objective methods of evaluation and gradation [13].

Preiser et al. [14] stated that it is required to apply and develop evaluation methods of BPE for different types of buildings. Foliente et al. [13] divide the building process into two parts, namely "initiation" and "application" by adding a pre-design phase to the process. The user needs and target performance are set between these two parts of "initiation" and "application". Design is structured towards reaching the target performance in the design phase, while the building performance is evaluated in the occupancy phase. Progressing in a linear structure, the process ends with the building being evaluated as a final product. Preiser, on the other hand, approaches the process in a cyclical manner (Figure 1). Certain questions are answered in the ongoing lifecycle of the building; the user requirements include the evaluation subject, performance measurements, and performance dimensions as well as informing the designer regarding the solutions for design, goals, scope, and program, guidelines, and standards. BPE is explained as evaluations, comparison of the evaluations to the performance measurements, and the determination of the success level of the building performance [14].

Similar to Preiser, Szigeti and Davis [11] argue that BPE can be applied at any time during the building process and used throughout the lifecycle of the building. The evaluation can be applied to the whole process, or a part of it [11], and any performance evaluation required 
later on in the process can be added at all times during the process.

Building performance evaluations are different from the evaluations towards measuring user's satisfaction. Performance evaluations grade the physical existence through a set of existing measurements and capacity indicators, then compares the results to required levels of performance. On the other hand, user's satisfaction measurements are performed through surveys measuring the perceptions of the building users. Both evaluation methods have their benefits [11] and they complement each other.


Figure 1. Progress and steps of Building Performance Evaluation according to Foliente (A) [13], and Preiser \& Vischer 2005 (B) [10]

Preiser and Schramm [15] define the total process of BPE in 6 steps (Figure 2). "Effectiveness review" includes the project designing and pre-design planning, covering the market analysis, identification of requirements, and evaluation of the benefits and alternative scenarios. As the second step of the BPE, "programme review" is directly connected to strategic planning. Program is required to determine the existing or possible user requirements, building qualifications, resources, problems, and solutions. "Design review" constitutes the third step of the BPE, covering the participation of parties in the actual process of creating spatial and physical solutions for the user, following the strategic planning and briefing.
"Commissioning" covers the program, business program, written and visual documents, licenses, contracts, and expected details regarding the building, as well as international guidelines, standards, local guidelines, and safety measurements. At the end of the process, building processes are examined periodically by authorized experts in accordance with legal standards and norms. "Post-occupancy evaluation" corresponds to a detailed and systematic evaluation of the buildings towards a certain purpose following their construction. The purpose of the post-occupancy evaluation is to assess the decisions on design and results of these decisions according to the requirements and reviews of the owners or occupants of the building. At the last step of BPE, "market/needs analysis" evaluates how to utilize the outer shell of the building or the level of adaptability and reusability of the building in manners of adapting to the new program. The end of this step presents the end of building performance evaluation [15]. Therefore, in the building performance evaluation approach, the ending point of this evolutionary cycle also constitutes the next building delivery cycle (Figure 2).



Figure 2. Building performance evaluation (BPE) process model [15]

This study is limited with the evaluation step defined as the "needs analysis step", as it examines the phase after the adaptive reuse process.

\subsection{Evaluation Methods and Performance Criteria}

Performance evaluation is critical in the betterment of buildings or determining the causes of problems regarding a building.

Building performance evaluation requires careful measurement of the performance criteria and adequate assessment methods. Regardless of the fulfillment of the requirements, the evaluation is based on the quality or characteristics of the building. Performance criteria should be measured thoroughly and assessed through adequate methods.

Evaluation of a building includes many performance criteria. The identification of the criteria is affected by many factors such as the purpose, duration, and depth of the evaluation. In a manner, criteria determined for the 
evaluation corresponds to the expected qualities of the building. The data that comes from the evaluation of these criteria constitutes the input for the quality, therefore, the performance of the building.

Practically, even if the selection of the performance criteria is performed by the administration or the researcher, the decisions regarding the criteria selection depend on the conditions and context under which the performance measurements are performed. Efficiency has always been the focal point of utmost importance in the performance criteria; however, user's requirements and criteria towards perception have gained importance in recent years. Building performance criteria can be grouped into various main topics (Table 1). This study embraces technical, functional, and behavioral criteria developed by Preiser [7], who studied and approached BPE comprehensively and holistically.

Performance measurements can make use of surveys, observations, interviews, archives, document collection, photographs, sound and visual recordings, physical measurements, and techniques regarding usage determination [14]. It is crucial to follow quantitatively calculable methods to evaluate the qualitative data objectively and systematically. The collection and evaluation of the data depend on the depth and duration of the research. As in post-occupancy evaluation techniques, 'the indicative level [14]' evaluation takes 2 to 3 hours, or 1 to 2 days, and defines the strength and weaknesses of the building. There are four methods of data collection: evaluation through archives and documentation, data collection through directing assessment surveys, data collection through photographing and observing, and interviewing. On the other hand, the 'investigative level [14]' covers a wider and more comprehensive examination based on literature review to identify the evaluation criteria.
The investigative level requires more time and resources compared to the indicative level as it gives the principal problems from the occupants themselves, and covers other sub-criterion such as lightning, image, security, acoustic, energy, and climate. It can make use of the same methods as the prior level; however, it requires more data and methods of analysis. 'The diagnostic level [14]', the most comprehensive evaluation amongst the three, is generally used for evaluating large-scale projects and makes use of multi-method strategies including questionnaires, observations, and physical evaluations. To fully conduct and complete an evaluation at the diagnostic level, requires more time and a team with high expertise.

\section{A Conceptual Framework for Adapted Building Performance Evaluation}

The conventional building performance evaluation approaches focus on the final product. However, building design and production is an ever-expanding process. Performance evaluation can be performed for a building throughout its lifecycle or a part of its lifecycle. Starting from the conditions that the building is required to be built, it continues using the building and even though its adaptive reuse process to begin again as a cycle. While extending the effective life of an existing building [19], adaptive reuse provides the new and/or changing needs of occupants to be fulfilled by installing a new purpose of use to the building. Evaluation for adaptive reuse refers to the process of systematic and detailed evaluation of the new uses of buildings. Even if the purpose of use of the building remains the same, the use of the interior spaces of a building constantly changes throughout its lifecycle.

Table 1. Performance criteria as stated by various researchers

\begin{tabular}{|c|c|c|c|c|c|}
\hline & $\begin{array}{c}\text { Preiser } \\
\text { [7] }\end{array}$ & $\begin{array}{c}\text { Lützkendorf et al. } \\
\text { [16] }\end{array}$ & $\begin{array}{c}\text { Voordt \& Wegen } \\
\text { [12] }\end{array}$ & $\begin{array}{c}\text { Yaldız } \\
\text { [17] }\end{array}$ & $\begin{array}{c}\text { Aksah et al. } \\
\text { [18] }\end{array}$ \\
\hline $\begin{array}{c}\text { Functional } \\
\text { Performance }\end{array}$ & $\checkmark$ & $\checkmark$ & $\checkmark$ & $\checkmark$ & $\checkmark$ \\
\hline $\begin{array}{c}\text { Technical } \\
\text { Performance }\end{array}$ & $\checkmark$ & $\checkmark$ & $\checkmark$ & $\checkmark$ & \\
\hline $\begin{array}{c}\text { Behavioral } \\
\text { Performance }\end{array}$ & $\checkmark$ & $\checkmark$ & $\checkmark$ & & \\
\hline $\begin{array}{c}\text { Economical } \\
\text { Performance }\end{array}$ & & $\checkmark$ & $\checkmark$ & & \\
\hline $\begin{array}{c}\text { Aesthetical } \\
\text { Performance }\end{array}$ & & & & & \\
\hline $\begin{array}{c}\text { Environmental } \\
\text { Performance }\end{array}$ & & $\checkmark$ & & $\checkmark$ & \\
\hline $\begin{array}{c}\text { Process } \\
\text { Performance }\end{array}$ & & $\checkmark$ & & & \\
\hline
\end{tabular}






Figure 3. Performance evaluation of adaptive reuse. Figure produced by the authors

This phase of building performance evaluation assesses the adaptability and reusability of a building not only in the manner of sustainable building implications but also in terms of adaptability towards new uses.

There may be differences in manners of performance between the buildings which are used for the purpose they have been built, and the buildings which are being adapted to a different use. The building can fully adapt its new purpose of the use or the expected level of performance of the building can decrease. The failure in providing harmony between the user and space leads to non-functional and uncomfortable designs, which can cause troubles in general usage and even malfunctioning of the building. For this reason, evaluation for adaptive reuse takes an important role in sustainable usage. By evaluating the feasibility and the user expectations, building performance evaluation enables prediction of the possible problems, betterment of the pain points, or healthier decision making in the adequate selection towards the new usage (Figure 3).

The new function installed in the existing building generates new requirements for the new occupants. With the general feasibility being added to these requirements, performance criteria to be evaluated are determined. The determination of the methods and criteria used in the evaluation of building performance depends on the performance dimension under which the building will be examined. Evaluation can be performed at various levels. Criteria can be identified focusing on a solution to a specific problem, or an evaluation can be performed at an indicative level to contribute to the identification of the problem. This study aims to perform an evaluation at an indicative level regarding technical, functional, and behavioral performances, present the strengths and weaknesses of the case study, and provide insight into further in-depth research based on solution-oriented criteria.

\subsection{Criteria of Functional Performance}

Every building has functional features which correspond to the purpose of the building. The change of use requires the adaptation of such features to the building envelope. In most cases, the selection of the new function considering these features leads to a positive response by the building to its new function. However, an inadequate purpose of reuse for the features of the building requires extensive intervention to the building envelope and space to adapt the building to its new purpose of use. Generally, in the building performance evaluation process, the questions to be answered are "is the building capacity for the program of the new function?", "are the existing spaces adequate for the new purposes of use?", "are the spatial organization and circulation adaptive to the new use?". The criteria, dependent on the buildings and the context, are determined in this study as "capacity" [10], [16], "spatial organization" [10], [16], [17], "accessibility" [10], [16], "dimensions of space" [17], [18], and "flexibility" [10], [16], [17].

Functional performance, which covers distinctive features and issues that occur during the usage process, can be evaluated through various required methods such as observations, measurements, interviews, and documentation reviews [7].

\subsection{Criteria of Technical Performance}

For the buildings which have gone through a small or medium-scaled adaptive reuse process, generally, the structural and technical conditions remain the same or improve. However, in some cases, false interventions can be performed to adapt the building to its new use. Also, in some cases, the technical performance of the building declines naturally, as a result of aging, independently of adaptive reuse. This might occur due to an impairment in the carrier system, or the facility technology might get out of date. Through periodical maintenance and repair, the technical performance of the building can be maintained at an ideal level according to the other performance criteria. Technical performance covers physical criteria such as structure, [10], [16], [17], safety and security [10], [20], comfort and health [16], [20] etc. Technical performance is evaluated through measurements by the use of technical measurement tools and comparison with the ideal conditions. 


\subsection{Criteria of Behavioral Performance}

It is considered that the functional and technical performance are directly related to the building qualities perceived by the inhabitants of the building [15]. The perceptions of the inhabitants take a role as important as the role of physical features in building performance evaluation. Behavioral performance relates the user activities and user's satisfaction with the use of the building and examines the effects of the building design on the psychological and sociological structure of the occupants. Behavioral performance is based on the examination of occupants' perception of the criteria evaluated within the context of functional performance, in terms of sufficiency and practicality. Likewise, criteria evaluated within the context of technical performance are examined in terms of safety, comfort, airiness, calmness, peacefulness etc. in behavioral performance.

Criteria of behavioral performance are evaluated following the comparison of data provided by methods such as interviews, surveys, and observations. As the result of the evaluation is affected by various factors such as the method, standards, and the occupants, buildings with the same physical features may have different results in case of being used in different periods by the same occupants, or by different occupants within the same time [7].

\subsection{Data Analysis}

Table 2. Score intervals for Likert scale with three scores

\begin{tabular}{|c|c|c|}
\hline Score & Response & Min \& Max Values \\
\hline 1 & Negative/Poor & $1,00-1,66$ \\
\hline 2 & Average/Neutral & $1,67-2,33$ \\
\hline 3 & Positive/Good & $2,34-3,00$ \\
\hline
\end{tabular}

The Likert scale can be used for evaluating the findings, as it is a quantitative scale widely used in the research at this level. Following the comparison of the data with ideal conditions and standards, outcomes with positive/good values are counted as " 3 ", outcomes with neutral values are counted as " 2 " and outcomes with negative/bad values are counted as "1", then all values are analyzed on the Likert scale. To enhance the depth of the analysis, the values of the scale can be increased to 5 or 7 . Following the determination of the performance of spaces through averaging the values of performance, a grading scale is constructed using the formula "Gap width=Series width/Number of groups", as $2 / 3=0.67$. According to this value, score intervals are constructed, as demonstrated in Table 2.

\section{Case Study: Performance Evaluation of Mugla Museum}

Located in Mentese, Mugla, Mugla Museum had served as a prison prior to its current function of the museum. Having remained out of use for a while following the termination of the prison function, a building survey had been conducted in 1990, and around those dates, restoration projects of the building had started. Again, during those dates, various fossils of animals and plants have been found as a result of the excavations in the area. The museum was opened to visitors in 1994, to exhibit those fossils.

Nature History Section hosts numerous fossils of animals and plants dating back to 9 million years ago. Ethnography Section exhibits local works, weaving goods, carpentry tools, and tools used in everyday life since the Republican Era until today. Archaeology Section covers the artifacts found in ancient cities within the borders of Mugla. Hall of Gladiators hosts seven tombstones of gladiator graves found in the ancient city of Stratonikeia. On these tombstones, the deceased people who had died during the gladiator fights are described. There is also a skeleton of a gladiator.
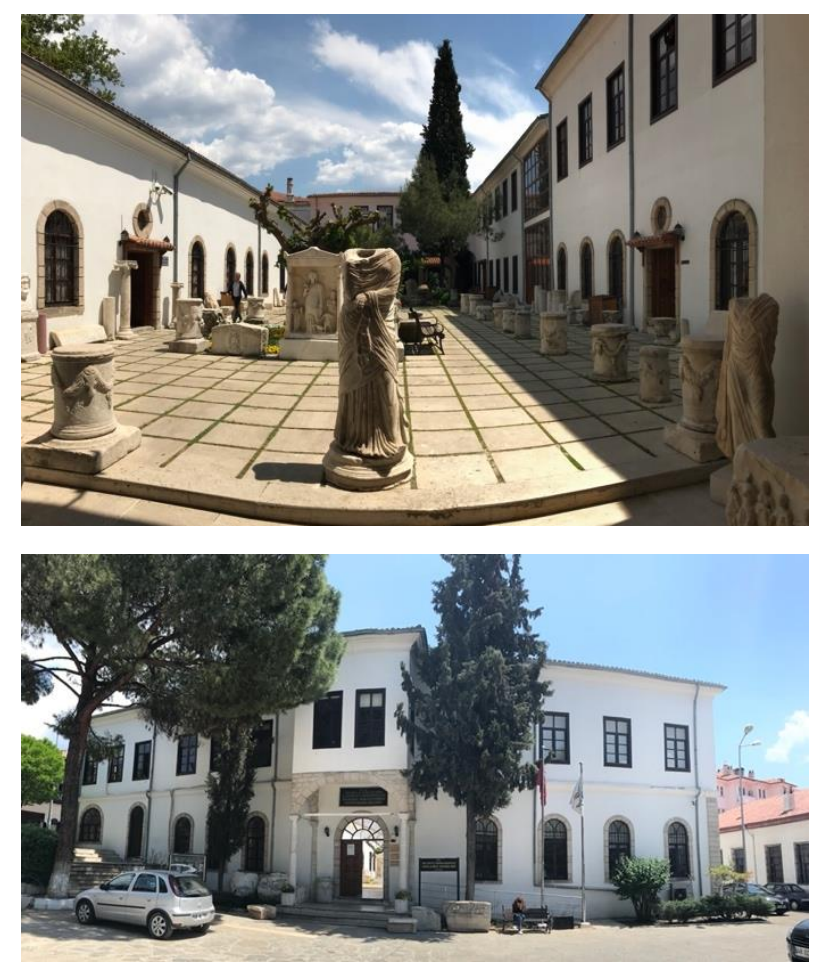

Figure 4. Views of Mugla Museum: Entrance façade (up) and the patio (down). Source: The Authors: 2021 

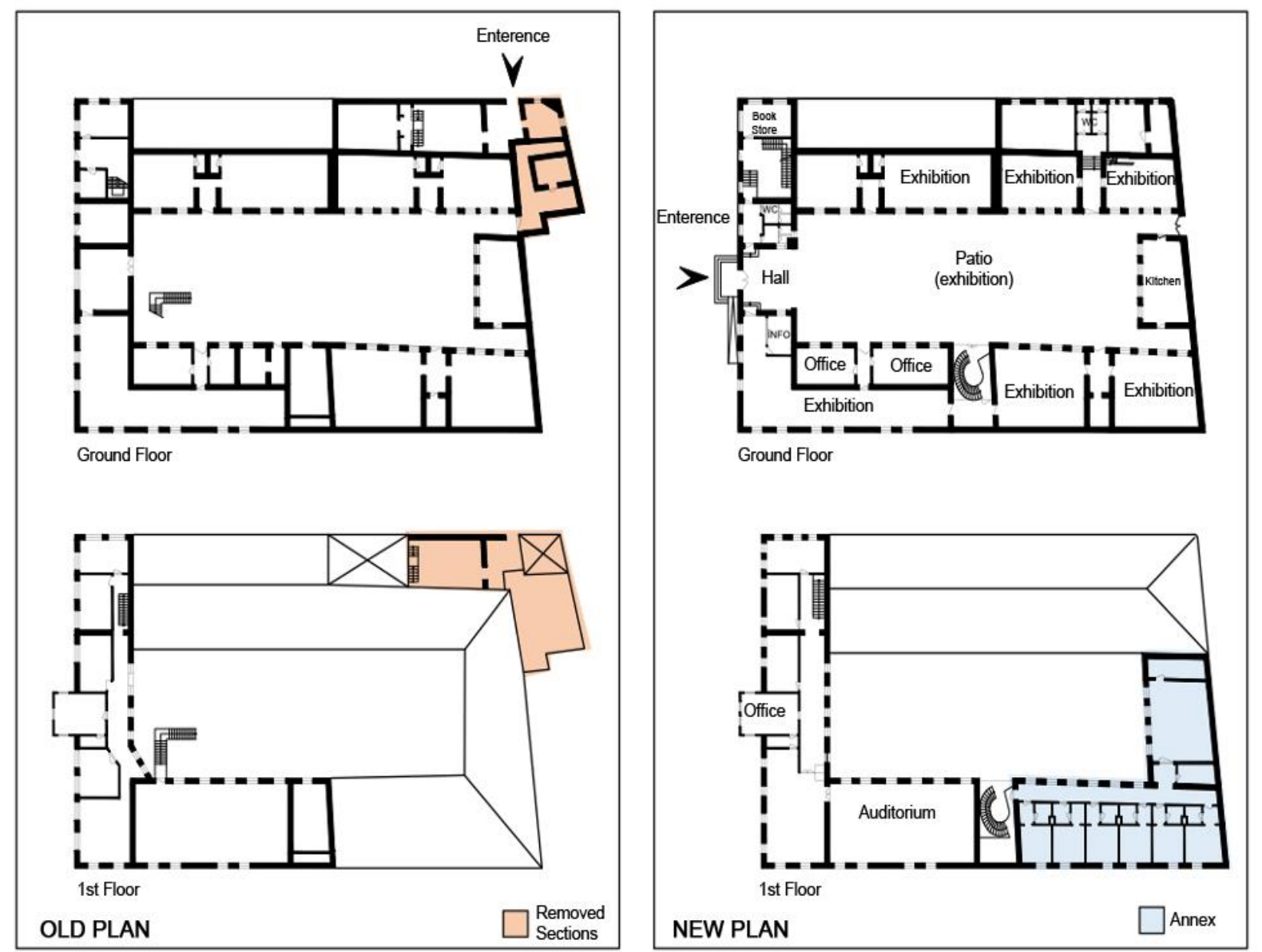

Figure 5. Before and after adaptive reuse of Mugla Museum. Image produced by the authors

\subsection{Adaptation of the Building from a Prison to Museum}

The former prison consists of various spaces cumulating around the patio. This linear system with a patio has been found appropriate for the museum function. Also defined as cellular spaces, this concept fits both the prison and museum functions. The documentation of the building surveys and restoration studies, achieved from the museum archive, demonstrates the differences between the old and new versions of the building (Figure 5)

The plan schemes clearly demonstrate the change in the entrance, which has majorly affected the entrance hall and circulation. Again, it is observed that the old entrance and the spaces connected to it have been removed. As a result of the requirements caused by the new use, an additional structure has been built on the upper floor of the building. The annex is built similar to the original building method and in accordance with design language. The new annex is observed to be indistinguishable from the original structure. However, the entrance façade, accommodating the rotational stairs reaching the meeting hall, has been designed as transparent and distinguishable, as seen on the visuals of the patio. Except for these differences, it can be concluded that the building has been preserved in terms of structure and originality.

The only inference regarding the then-structure of the building, from the building archive survey dated 1990, is the linear plan of the cellular spaces towards the opening to a patio (Figure 5). It can be inferred that the prisoners had been staying in these cells and sometimes they spent their time on the patio. The new spaces constituting the museum have been adapted in accordance with these cells (Figure 6). The offices, which are the administrative units of the museum, have been similarly placed to the cellular spaces. The patio of the prison adapted to the open exhibition and circulation functions, exposing the objects exhibited in the open and circulation to open weather conditions.

The museum accommodates exhibitions in different concepts, an art gallery, conference hall, and auxiliary spaces in the spaces accumulated around the patio hosting ancient ruins and sculptures. This diversity increases the attractiveness of the museum while resulting in a requirement for more space. 

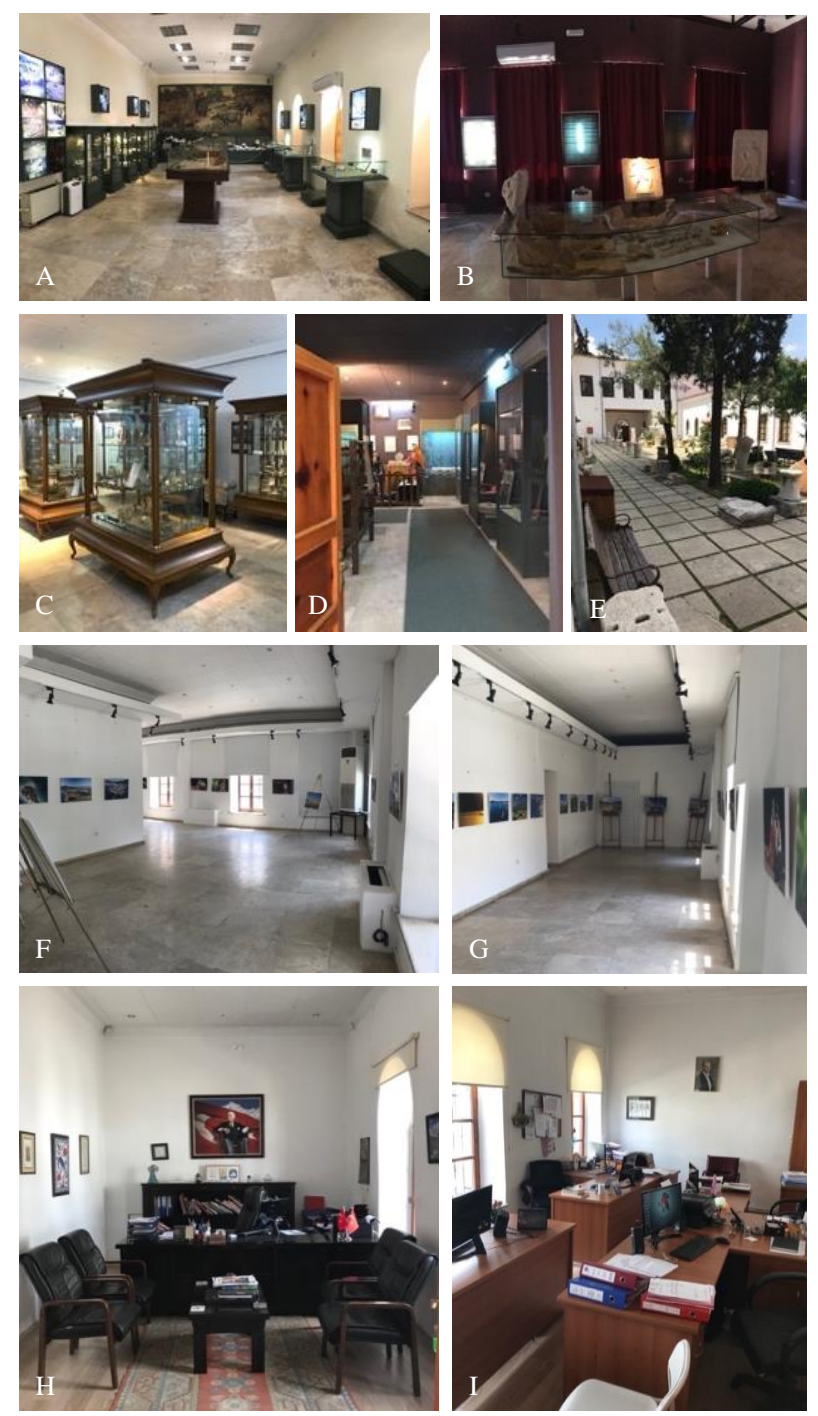

Figure 6. Nature Exhibition (A), Gladiators Exhibition (B), Archaeology Exhibition (C), Ethnography Exhibition (D), Patio (E), Temporary Exhibition (F,G), Director's Office (H), Personnels' Office (I). Source: The Authors: 2021

\subsection{Determination and Measurement of Performance Criteria}

The technical, functional, and behavioral performance classification has been embraced by this study for the performance evaluation of the Mugla Museum. The strengths and weaknesses of the building have been set forth through the use of these criteria. In-depth further research for the determined problems of the building can be performed separately. This study does not include the environmental, social, and aesthetical performance criteria which are affected in adaptive reuse. Four exhibition spaces, two offices, a kitchen, recreational space, the entrance, and the patio, which is also the open exhibition area, have been evaluated. Spaces located on the upper floor (storage, archive, other administrative uses, etc.) have not been included in this study. The criteria for the case study are as follows:

\section{- Functional Performance}

- Capacity

- Spatial organization and circulation

- Accessibility

- Dimensions of space

- Flexibility

\section{- Technical Performance}

- Structure

- Fire safety

- Visual quality

- $\quad$ Auditory quality

- Thermal quality

- Air quality

\section{- Behavioral Performance}

- Sufficiency

- Practicality

- Safety

- Comfortable

- Airiness

- Calmness

- Facility

- Peacefulness

Analysis regarding the feasibility of the building is combined with the analysis of the data gained from the constant occupants of the building, then supported by visual materials such as computer-aided technical drawings and photographs.

\subsubsection{Evaluation of Functional Performance}

\section{- Capacity}

Spatial program defines the spaces a design includes, while the qualities of the spaces provide information about the design. The quality and functional capacity of spaces provide important input about the potential uses of the space in reuse. Therefore, the success of adaptive reuse depends on the correspondence between the existing qualities and the requirements of the new function [20].

Besides their exhibition function, museums function as cultural centers. Therefore, the program of museum buildings should include multi-purpose spaces. Primary spaces museums should include permanent and temporary exhibition units, working and research spaces, a library, conference hall, a cafeteria, restaurant, storage units, studios, and administrative units [21]. It has been observed that the building program of Mugla Museum lacks public spaces such as a cafeteria, restaurant, and library. The diversity of exhibition spaces, which also constitute the primary spaces, causes insufficiency of the storage areas. Besides, the lack of capacity of the building causes a lot of works and pieces to be stored in the storage spaces without being exhibited.

- Spatial organization and circulation

As the new building program demonstrates, the 
exhibition units and the spaces of common use will be the spaces hosting the highest visitor density. Given their function, the exhibition units of Mugla Museum are considered to correspond to the use of individual uses of temporary users (visitors), common use areas are intended for the use of both individual and collective uses, and the administrative units are planned for the use of permanent occupants. For this reason, the planning of the spaces adjacent to the building entrance towards corresponding exhibition function and collective uses is considered appropriate, as it prevents the redundant circulation of the building personnel. For the evaluation of the building in terms of use, it is inferred that ground-floor spaces are organized for this purpose. The relation between spaces and horizontal circulation has been considered positive.

\section{- Accessibility}

Access to the building from the main entrance is provided through a three-step staircase. The platform adjacent to the steps is adequate for the use of the elder and the handicapped occupants, in terms of dimensions and elevation. Although the building and the primary spaces located on the ground floor are easily accessed, the two-story building has been observed to not have an elevator, constituting a problem in the vertical circulation. Even though the primary spaces used by temporary occupants are located on the ground floor, the lack of an elevator is considered negative for the sake of elder and handicapped occupants who might seek to access the conference hall and other administrative units. Similarly, the wet areas located on the ground floor differ from the circulation spaces in terms of elevation and are accessed only through elevated steps, preventing the use of handicapped occupants. As a result of the observation, the accessibility level of the building has been considered neutral.

\section{- Dimensions of space}

It is known that the dimension determination process in space design is affected by occupant qualities, occupant activities, tools used in the activities and movement area. The smallest unit in space evaluation is defined as "usage unit [20]. Based on the usage unit, this study adopts performing function-based analyses on the selected spaces. In the determination of the dimensions of activity areas, required tools (furnishing elements), performed activities, and occupant movement areas are the main factors. Considering the functions in terms of required sizes, the dimensions of the exhibition spaces are found to be sufficient. However, in terms of size, the office space has been found insufficient in accommodating 4 working people at the same time. The unit functioning as a kitchen and recreation area is also used as the dining area of the personnel. This area has also been found insufficient in terms of sizes, as it lacks the dimensions to accommodate sufficient facilities for all of the personnel to dine and rest in the unit at the same time.

\begin{abstract}
- Flexibility
It has been observed that the masonry work construction of the building had eliminated the possibility of removal of the main walls in order to unite the spaces. Similarly, it is not possible to divide the spaces through divisive components where the dimensions are insufficient. The only space capable of being divided is the temporary exhibition area, which does not require to be divided considering its function. The incapability to be divided or united is considered as a constraint on the possible changes in the use in the coming times. Therefore, the flexibility of the spaces has been evaluated as negative.
\end{abstract}

\subsubsection{Evaluation of Technical Performance}

\section{- Structure}

The building has been built following the masonry design rules. In terms of basic evaluation, the spaces allowed by the building system, dimensions of the carrier system, and the walling method have been evaluated as positive. There is no impairment observed in the system. Also, there is no illegal structuring or intervention to the original carrier. The annex structure has been observed to follow the original system. As a result, the structure of the Mugla Museum building has been evaluated as positive, although the result of the evaluation can change in case of research in further levels.

\section{- Fire safety}

Fire safety of the building has been examined through the signal elements, extinction elements, and escape plan. The examined spaces are observed to include smoke detectors' inadequate location and number. The fire extinguisher tubes have been found accessible in related locations. However, the lack of a fire escape ladder causes inconvenience in escaping from the upper floor. There, the fire safety of the building has been evaluated as neutral.

\section{- Visual quality}

As the main element of lightning design for museums is the exhibited object, ideal visual perception of the object and the comfort of the occupants during visual contact with the object or objects have great importance [22]. As accepted by the Illuminating Engineering Society (IES), the required level of luminousness is 200 lux for museums and 400 lux for offices [23]. The required level of luminousness varies according to the sections of the space and the type of exhibited object. Exhibition objects are classified as very sensitive to light, moderately sensitive to light, and non-sensitive to light. Ideal luminousness levels are determined according to their level of sensitivity. As stated in the IESNA Guide for Lighting, the minimum and maximum required luminousness level depend on the age and capacity to see the observer. The maximum luminousness levels to enlighten the objects without any harm, determined according to this classification [23], have been taken into consideration in measuring through the use 
of Lightmeter application. Generally, the lighting of the spaces is insufficient/negative, since the entrance and the patio that are open spaces without any shade elements would lead to the discomfort of the eye.

\section{- Auditory quality}

Acceptable levels of noise are defined as the noise levels which would not discomfort the human ear in open and indoor spaces, according to the functions fulfilled. Acceptable levels also vary according to the individual, social, psychological, etc. factors [24]. Within the context of this study, the noise level of Mugla Museum has been measured through the mobile application "Decibel X", ignoring the individual, social and psychological factors, and the results have been compared with the comfort standards determined by BSI [24]. Although the noise level of 38-56 dB measured in exhibition areas, $65 \mathrm{~dB}$ in entrance and patio, and $60 \mathrm{~dB}$ in kitchen and recreation area could be considered as acceptable. It should be taken into consideration that these levels are measured during hours without any visitors, and the increase in the number of visitors would also cause an increase in the noise level, therefore, the comfort of the space in an acoustic manner. The $60 \mathrm{~dB}$ measured in the office spaces has not been considered acceptable for working spaces, as the auditory discomfort could lead to a lack of concentration in officers and a decrease in work efficiency. The auditory quality of the spaces of Mugla Museum can be evaluated as neutral.

\section{- Thermal quality}

Besides the visual and auditory quality, thermal quality has great importance, especially for the occupants [22], [25]. Concepts considering thermal quality also enhance the conditions of comfort in the building [26]. Thermal temperature measurements in spaces naturally vary according to the factors such as the season and the hour of measurement. In measurements related to thermal quality, dimensions related to humidity and air movement are ignored. This study takes thermal comfort measurement as a one-time measurement of temperature, and it is possible that the outcome value would vary when measured in a different season, day, or hour. It is possible that the relation between the felt temperature and comfort may differ in different spaces and functions (working by sitting: $21^{\circ} \mathrm{C}$, walking during a visit: $16^{\circ} \mathrm{C}$, storage: $12^{\circ} \mathrm{C}$ ) [22]. The temperature of the open spaces and the entrance is normal, as the temperature of the other spaces has been measured as lower than ideal. The temperature in the spaces has not been considered to create discomfort as the measurement has been conducted during the spring and the clothes have been chosen accordingly. However, in the office spaces, the insufficiency of air conditioning and the decrease in temperature of the space have been considered as negative as to harm the work efficiency of the personnel. In this manner, the overall thermal quality has been evaluated as neutral.

\begin{abstract}
- Air quality
The design of the building is a concept with cellular spaces opening to a patio, which allows for windows and natural ventilation for each space. The exhibition spaces require windows to be closed. In these spaces, ventilation should be performed artificially and by the use of moisture devices. The measurement of air quality requires technical and detailed studies. As this study adopts a basic level evaluation, the air quality of the space has been basically observed and considered as positive in general since the exhibition spaces accommodate artificial ventilation and each space has the opportunity for natural ventilation.
\end{abstract}

\subsubsection{Behavioral Performance Evaluation}

Semi-structured interviews with 5 occupants have been performed to measure the behavioral performance of the building. The occupants' profile consists of the permanent occupants which are skilled and technical staff; museum director (administrative staff), archaeologist (skilled staff), and art historian (skilled staff) are selected since their expertise is related to the museum and art pieces. Also, the security staff and janitors have been selected since they also constitute the permanent occupants of the building. It should be noted that interviews conducted at different periods with different persons may also have different results. The aim of the semi-structured interviews is both to compare the results of the technical and functional performance measurements with the effects on the building occupants and to expand the context of the interview by reaching different problems or sub-problems through the professional and usage experiences of the interviewees.

The interviews have examined the values on sufficiency, practicality, and safety relating to the building generally, and values of comfortable, airiness, calmness, facility, peacefulness relating to each of the exhibition and working spaces. The values have been digitized in accordance with the 3 points Likert scale as "good", "poor" and "neutral". The arithmetic average of the responses of the participants has been assessed through their value on the Likert scale. Validity and reliability tests have not been performed considering the number of participants is 5 .

Certain spatial requirements have been found as a result of the interview with the administrative staff. It has been found that the administrative staff, who, except the museum director, work at the office spaces with the capacity of 4-5 people, have the request to have independent offices. The wet areas are open for the common use of the visitors and the administrative and technical staff. It has been informed that the administrative staff requests the wet areas to be increased in numbers, with a separation from the visitors' use.

The skilled staff has stated that the exhibition spaces are insufficient. Due to the lack of exhibition areas, there are a lot more unexhibited objects stored in the storage, than the exhibited pieces. The skilled staff has also added that the pieces which are exhibited in the patio are not appropriate 
for open-air exhibition, and they need to be conserved. They have stated that they are content with the visual and auditory comfort level of the spaces, except the cold air during the winter, caused by the insufficiency of air conditioning. Especially for office spaces, thermal comfort is absent during winter, according to the interviews.

The major problem stated by the skilled staff is the low frequency of the visitors to the museum, with the staff relating this problem with the lack of popularity and accessibility of the museum. The skilled staff has declared that a newer and bigger building would present a more prestigious museum, and the increase in exhibition spaces would result in a higher frequency of visits.

Certain spatial requirements have also been detected as a result of the interview with the technical staff. The first problem is that for the whole personnel there is only one recreation area, which also includes the kitchen and the dining area. It has been stated that they need to be customized, individual spaces for their free time, such as a separate kitchen, customized resting spaces, smoking areas, etc. Apart from these, the personnel have evaluated the visual, auditory, and thermal comfort of the space they use (kitchen and recreation area) as positive.

\subsection{Results of Performance Evaluation}

For the performance evaluation study for Mugla Museum, the values corresponding to "good", "poor" and "neutral" have been calculated according to the Likert scale and averaged arithmetically (Table 5).
According to the general results of the findings relating to the functional performance of the building, the dimensions of the space have been found to be "good" $(X=2.60)$, the flexibility of the space has been found to be "poor" $(\mathrm{X}=1.20)$, capacity has been found to be "poor" $(\mathrm{X}=1.00)$, spatial organization and circulation have been found to be "good" $(\mathrm{X}=3.00)$ and accessibility has been found to be "neutral" $(\mathrm{X}=2.00)$. According to the general average of technical performance of the spaces, the visual quality has been found to be "poor" $(\mathrm{X}=1.30)$, the auditory quality has been found to be "neutral" $(\mathrm{X}=1.88)$, the thermal quality has been determined to be "neutral" $(X=2.00)$ and the air quality has been found to be "good" $(X=3.00)$. According to the average of the values digitized from the analyses of the statements given by the occupants during the interviews, the sufficiency level of the building has been found to be "poor" $(X=1.20)$, while the values of practicality $(X=2.40)$ and safety $(X=2.88)$ have been determined as "good". The average of the perceptive performance evaluation shows that the spaces have been evaluated as comfortable, airy, calm, and peaceful $(\mathrm{X}>2.34)$

Total results of performance have been achieved through combining the spatial data with the data related to the building (Table 6). The technical performance of the building has been found to be "good" $(\mathrm{X}=2.35)$, while the functional $(X=2.18)$ and perceptive performances $(X=2.26)$ have been determined as "neutral". It can be concluded that the building corresponds to the adaptive reuse process at a neutral-good level. 
Table 3. Performance evaluation of the adapted space

\begin{tabular}{|c|c|c|c|c|c|c|c|c|c|c|c|c|}
\hline & & \multicolumn{2}{|c|}{ Functional Performance } & \multicolumn{4}{|c|}{$\begin{array}{c}\text { Technical } \\
\text { Performance }\end{array}$} & \multicolumn{5}{|c|}{$\begin{array}{c}\text { Behavioral } \\
\text { Performance }\end{array}$} \\
\hline & & $\begin{array}{c}\text { Dimensions } \\
\text { of space }\end{array}$ & Flexibility & $\begin{array}{l}\text { Visual } \\
\text { quality }\end{array}$ & $\begin{array}{c}\text { Auditory } \\
\text { quality }\end{array}$ & $\begin{array}{c}\text { Thermal } \\
\text { quality }\end{array}$ & Air quality & Facility & Airiness & Calmness & Comfortable & Peacefulness \\
\hline & Mean & 2,60 & 1,20 & 1,30 & 1,88 & 2,00 & 3,00 & 2,50 & 2,34 & 2,78 & 2,74 & 2,72 \\
\hline \multirow{10}{*}{ Space } & Hall & 3,00 & 1,00 & 1,00 & 1,00 & - & 3,00 & 3,00 & 3,00 & 3,00 & 3,00 & 3,00 \\
\hline & Patio & 3,00 & 1,00 & 1,00 & 1,00 & - & 3,00 & 3,00 & 3,00 & 3,00 & 3,00 & 3,00 \\
\hline & Nature History Section & 3,00 & 1,00 & 1,00 & 3,00 & 2,00 & 3,00 & 3,00 & 3,00 & 3,00 & 3,00 & 3,00 \\
\hline & Hall of Gladiators & 3,00 & 1,00 & 1,00 & 3,00 & 2,00 & 3,00 & 1,80 & 1,00 & 3,00 & 3,00 & 2,60 \\
\hline & Archaeology Section & 3,00 & 1,00 & 1,00 & 1,00 & 2,00 & 3,00 & 2,60 & 1,80 & 3,00 & 3,00 & 3,00 \\
\hline & Ethnography Section & 3,00 & 1,00 & 1,00 & 3,00 & 2,00 & 3,00 & 2,60 & 2,60 & 3,00 & 3,00 & 3,00 \\
\hline & Temporary Exhibition & 3,00 & 3,00 & 1,00 & 3,00 & 2,00 & 3,00 & 3,00 & 3,00 & 3,00 & 2,80 & 3,00 \\
\hline & Director's Office & 3,00 & 1,00 & 1,00 & 1,00 & 2,00 & 3,00 & 3,00 & 3,00 & 3,00 & 3,00 & 3,00 \\
\hline & Personnel's Office & 1,00 & 1,00 & 3,00 & 1,00 & 2,00 & 3,00 & 1,00 & 1,00 & 1,80 & 1,80 & 1,80 \\
\hline & Kitchen and Rest & 1,00 & 1,00 & 2,00 & 1,80 & 2,00 & 3,00 & 2,00 & 2,00 & 2,00 & 1,80 & 1,80 \\
\hline \multicolumn{2}{|c|}{ Spatial Performance } & \multicolumn{2}{|c|}{1,90} & \multicolumn{4}{|c|}{2,05} & \multicolumn{5}{|c|}{2,62} \\
\hline
\end{tabular}

Table 4. Total performance results of Mugla Museum

\begin{tabular}{|c|c|c|c|c|c|c|c|c|c|c|c|c|}
\hline & \multicolumn{5}{|c|}{$\begin{array}{c}\text { Functional } \\
\text { Performance }\end{array}$} & \multicolumn{3}{|c|}{$\begin{array}{c}\text { Technical } \\
\text { Performance }\end{array}$} & \multicolumn{4}{|c|}{$\begin{array}{c}\text { Behavioral } \\
\text { Performance }\end{array}$} \\
\hline & $\begin{array}{c}\text { Spatial } \\
\text { Performance }\end{array}$ & Capacity & $\begin{array}{c}\text { Spatial } \\
\text { Organization }\end{array}$ & Circulation & Accessibility & $\begin{array}{c}\text { Spatial } \\
\text { Performance }\end{array}$ & Structure & $\begin{array}{c}\text { Fire } \\
\text { Safety }\end{array}$ & $\begin{array}{c}\text { Spatial } \\
\text { Performance } \\
\end{array}$ & Sufficiency & Practicality & Safety \\
\hline Building Score & 1,90 & 1,00 & 3,00 & 3,00 & 2,00 & 2,05 & 3,00 & 2,00 & 2,62 & 1,20 & 2,40 & 2,80 \\
\hline Mean & \multicolumn{5}{|c|}{2,18} & \multicolumn{3}{|c|}{2,35} & \multicolumn{4}{|c|}{2,26} \\
\hline Evaluating & \multicolumn{5}{|c|}{ Neutral } & \multicolumn{3}{|c|}{ Good } & \multicolumn{4}{|c|}{ Neutral } \\
\hline
\end{tabular}




\section{Conclusion}

The ideal building design process is conceptualized based on the feedback given by the building performance evaluations, in order to provide guidance for future design assumptions. The aim is to always develop a better solution. Feedback is updated according to certain data collected from the building type evaluation studies. This is crucial and necessary in order to increase the quality of the buildings [10]. Criteria affecting the building performance and the relation between them can vary from one building to another. Contingent methods should be applied in the development of the performance criteria, determination of the aimed performance, and development and approval of the performance evaluation and grading tools [13].

Compared to new buildings, it has been observed that older buildings can also achieve ideal performance levels in case of the application of the right interventions. Although it does not fully correspond to the requirements of a museum in terms of spatial organization, Mugla Museum has the quality of fulfilling the occupant requirements by means of technical performance. A general evaluation at a basic level provides information on only the strengths and weaknesses of the building. This information provides a structure for the development and selection of the performance criteria for further research as well as offering a logical framework. In order to determine the sources of the problems determined during the study, it is required to expand the expert team and conduct deeper research. Besides, research regarding the variables which have not been taken into consideration during this study, such as environmental performance, economic performance, and aesthetical performance, would reveal different advantages and disadvantages of the building.

The building has gone through certain structural and technical changes. While some spaces have been able to fulfill the requirements of the new use, others have failed to correspond to them. The measurements regarding the functional and technical performance of the building can differ from the perception of the occupant. As an example of this, the fire safety of the building has been evaluated as "neutral" as given by the technical performance data, while the building has been stated as "safe" by the occupants.

Values of functional and technical performance may not always coincide with the perceptive performance values, due to the fact that the physiological and psychological conditions of the occupant have a direct effect on the result. In case, the same study would be conducted on the same building with different occupants, the technical and functional performance values may result similarly while the values of perceptive performance may dramatically differ. For this reason, in case of a need for further research regarding perceptive performance, it should be conducted by a multidisciplinary team with a wider interviewee group.

The building of Mugla Museum corresponds to the requirements of its new use with an average performance.
The level of performance has the potential to be increased through arrangements to the building program or an increase in the capacity of the building. It can be concluded that in terms of performance evaluation, the building has gone through an adequate process of adaptive reuse. The reuse and the new function of the building have been evaluated as positive and beneficial.

\section{Acknowledgment}

The authors would like to acknowledge that this paper is submitted in partial fulfillment of the requirements for the Ph.D. degree at Yildiz Technical University.

\section{Conflict of Interest}

The authors confirm that they have no conflicts of interest to declare.

\section{REFERENCES}

[1] J. Douglas, "Building Adaptation," Routledge, United Kingdom, 2006, DOI: 10.4324/9780080458519.

[2] S. J. Wilkinson, H. Remøy, C. Langston, "Sustainable Building Adaptation,", Wiley-Blackwell, 2014.

[3] G. Yıldız, N. Şahin Güçhan, "An Industrial Heritage Case Study In Ayvalik: Ertem Olive Oil Factory," Journal of Contemporary Urban Affairs, vol. 2, no. 3, pp. 22, 2018. DOI: 10.25034/ijcua.2018.4715.

[4] S. G. Akdağ and B. Sayar, "Revitalization and Adaptive Re-use in Cappadocia: A Taxonomy of Creative Design Solutions for Uchisar Boutique Hotels," Journal of Contemporary Urban Affairs, vol. 4, no. 2, pp. 37-50, 2020. DOI: $10.25034 /$ ijcua.2020.v4n2-4.

[5] A. Sulimowska-Ociepka, "Glass Structures in Post-Industrial Buildings and the Role of the Industrial Heritage in Shaping Creative Urban Spaces," Civil Engineering and Architecture, vol. 9, no. 2, pp. 281-292, 2021, DOI: 10.13189/cea.2021.090202.

[6] B. Lin, H. Chen, Q. Yu, X. Zhou, S. Lv, Q. He, Z. Li , "MOOSAS - A systematic solution for multiple objective building performance optimization in the early design stage," Build. Environ., vol. 200, 2021, doi: 10.1016/j.buildenv.2021.107929.

[7] W. F. E. Preiser, "Building Evaluation," Springer US, 1989.

[8] E. J. Gibson, "Working With The Performance Approach in Building," Report of Working Commission W60, CIB., 1982.

https://www.irbnet.de/daten/iconda/CIB_DC23969.pdf.

[9] B. Ülker, A. Kanoğlu, and Ö. Özçevik, "SIMURG CITIES: Meta-Analysis for KPI's of Layer-Based Approach in Sustainability Assessment" Journal of Contemporary Urban Affairs, vol. 5, no. 1, pp. 59-76, 2021. DOI: 10.25034/ijcua.2021.v5n1-5. 
[10] W. F. E. Preiser, J.C. Vischer, "Assessing Building Performance", Elsevier, UK, 2005.

[11] F. Szigeti, G. Davis, "Performance based building: Conceptual framework." CIB, 2005.

[12] D. van der Voordt, H. van Wegen, "Architecture In Use," Routledge, UK, 2007.

[13] G. Foliente, R. H. Leicester, L. Pham, "Development of the CIB Proactive Program on Performance Based Building Codes and Standards," CIB, 1998, http://cibworld.xs4all.nl /pebbu_dl/resources/literature/downloads/01General/07Fol iente.pdf.

[14] W. F. E. Preiser, E. White, H. Rabinowitz, "Post-Occupancy Evaluation (Routledge Revivals)," Routledge, USA, 2015.

[15] W. F. E. Preiser and U. Schramm, "A Conceptual Framework for Building Performance Evaluation" in Assesing Building Performance, Elsevier, 2005, p. 17.

[16] T. Lützkendorf, T. Speer, F. Szigeti, and G. Davis, "A Comparison of International Classifications for Performance Requirements And Building Performance Categories Used In Evaluation Methods," in Proceedings of 11th joint CIB International Symposium, pp. 1-19, 2005.

[17] E. Yaldiz, "Anıtsal Yapıların Kullanım Sürecinde Değerlendirilmesine Yönelik Bir Model Önerisi [A Model Proposal Aimed At The Post Occupancy Evaluation Of Monumental Buildings], " Ph.D. Thesis, Selçuk University, Turkey, 2013.

[18] H. Aksah, A. H. Nawawi, A. E. Hashim, E. Dewiyana, "Assessing Score of Applicability and Importance on Functional Performance Criteria for Historical Building," Procedia - Soc. Behav. Sci., vol. 222, pp. 65-74, 2016, DOI: 10.1016/j.sbspro.2016.05.188.
[19] C. Langston, E. H.-K. Yung, E. H.-W. Chan, "The Application Of ARP Modelling To Adaptive Reuse Projects in Hong Kong," Habitat Int., vol. 40, pp. 233-243, 2013, DOI: 10.1016/j.habitatint.2013.05.002.

[20] D. Aydın and E. Yaldız, "Yeniden Kullanıma Adaptasyonda Bina Performansının Kullanıcılar Üzerinden Değerlendirilmesi [Assessment of building performance in a re-use adaptation case], " METU J. Fac. Archit., vol. 27, no. 1, pp. 1-22, 2010, DOI: 10.4305/METU.JFA.2010.1.1.

[21] E. Neufert, "Yap1 Tasarımı [Architects' Data]," Beta Basım, Turkey, 2015.

[22] S. Saraoui, A. Belakehal, A. Attar, and A. Bennadji, "Evaluation of the Thermal Comfort in the Design of the Museum Routes: The Thermal Topology, " Journal of Contemporary Urban Affairs, vol. 2, no. 3, pp. 122-136, 2018. DOI: 10.25034/ijcua.2018.4727.

[23] M. S. Rea, "The IESNA Lighting Handbook," Illuminating Engineering Society of North America, USA, 2000.

[24] BSI, "BS 8233:1999 Sound Insulation And Noise Reduction For Buildings. Code Of Practice," BSI Standards Limited, 1999. doi: https://doi.org/10.3403/01833246.

[25] F. Z. Çağlar, G. Z. Gedik, H. Gökdemir, "The Impact Of Transparency Ratio On Thermal Comfort: A Field Study On Educational Building," Civil Engineering and Architecture, vol. 8, no. 5, pp. 890-897, 2020, DOI: 10.13189/cea.2020.080516.

[26] A. Shandilya, M. Hauer, W. Streicher, "Optimization Of Thermal Behavior And Energy Efficiency Of A Residential House Using Energy Retrofitting In Different Climates," Civil Engineering and Architecture, vol. 8, no. 3, pp. 335349, 2020, DOI: 10.13189/cea.2020.080318. 